REPRODUCTION

\title{
Reproductive cloning combined with genetic modification
}

C Strong

$\ldots \ldots \ldots \ldots \ldots \ldots \ldots$

J Med Ethics 2005;31:654-658. doi: 10.1136/jme.2004.011189

Correspondence to:

C Strong, Department of

Human Values and Ethics,

College of Medicine,

University of Tennessee

Health Science Center,

956 Court Avenue, Suite

B324, Memphis,

Tennessee 38163, USA;

cstrong@utmem.edu

Received

11 November 2004

In revised form

5 January 2005

Accepted for publication

20 January 2005

\begin{abstract}
Although there is widespread opposition to reproductive cloning, some have argued that its use by infertile couples to have genetically related children would be ethically justifiable. Others have suggested that lesbian or gay couples might wish to use cloning to have genetically related children. Most of the main objections to human reproductive cloning are based on the child's lack of unique nuclear DNA. In the future, it may be possible safely to create children using cloning combined with genetic modifications, so that they have unique nuclear DNA. The genetic modifications could be aimed at giving such children genetic characteristics of both members of the couple concerned. Thus, cloning combined with genetic modification could be appealing to infertile, lesbian, or gay couples who seek genetically related children who have genetic characteristics of both members. In such scenarios, the various objections to human reproductive cloning that are based on the lack of genetic uniqueness would no longer be applicable. The author argues that it would be ethically justifiable for such couples to create children in this manner, assuming these techniques could be used safely.
\end{abstract}

l: has been argued that the use of cloning by infertile couples to have genetically related children would be ethically justifiable. ${ }^{1}$ It has also been suggested that lesbian or gay couples might wish to use cloning as a way to have genetically related children. ${ }^{2}$ This article explores the ethics of using cloning combined with genetic modification to produce genetically related children. A caveat should be stated at the outset, however. Cloning research in animals has shown that a high percentage of cloned embryos do not successfully implant or gestate, presumably because of genetic abnormalities. There have also been reports of cloned animal fetuses and offspring with serious congenital malformations. ${ }^{3}$ Clearly, the risks to offspring constitute a conclusive argument against human reproductive cloning at this time. In the future, however, it is possible that our technology will permit cloning with no more risk to offspring than that involved in natural procreation. For the sake of argument, let us assume that cloning technology has advanced to that point, opening the way to address other pros and cons of human reproductive cloning. Similarly, developing the technology to perform genetic modifications safely in humans is likely to be difficult. Whether the complications involved can be overcome remains uncertain. Nevertheless, there is no good reason to rule out the possibility that, given enough time, researchers will surmount the obstacles.

It could be objected that cloning combined with genetic modification is too speculative and futuristic to deserve our attention. In reply, this objection overlooks the fact that currently there is a vigorous worldwide debate on the ethics of human cloning. It is relevant to that ongoing debate to argue, as I shall do in this article, that technological advances in cloning and genetic modification can thoroughly undermine many of the main objections to human reproductive cloning. Discussing futuristic scenarios can be worth while when doing so casts new light on current debates.

Most of the main objections to human reproductive cloning are based on the claim that these children would lack genetic uniqueness. It is alleged that this would harm the children, ${ }^{45}$ fail to treat them with respect, ${ }^{6-8}$ harm society, ${ }^{69}$ and violate human dignity. ${ }^{10}$ In response, it has been argued that it is a mistake to believe that children who have the same nuclear DNA as someone else will lack uniqueness. ${ }^{11}$ For one thing, the imprinting of a child's DNA could differ from that of his or her progenitor (the person who is the source of his or her nuclear DNA), resulting in phenotypic differences even though they have the same nuclear DNA. ${ }^{12}$ Even if the imprinting is the same, the child will be exposed to different uterine and social environments compared with the progenitor. ${ }^{13}{ }^{14}$ Divergent social environments are expected to result in different attitudes, goals, and life choices. Moreover, cloning does not duplicate the brain. As the brain develops in a growing child, neural connections are made in response to environmental stimuli. Different stimuli result in different patterns of connections. ${ }^{15}{ }^{16}$ The child's brain will vary in many ways from that of the progenitor.

Despite these persuasive arguments, opponents of cloning continue to put forward the objections based on lack of uniqueness. An example is Leon Kass and the President's Council on Bioethics, who have continued to propound these objections even after the publication of the responses mentioned above. ${ }^{511}{ }^{13-16}$ Although it seems reasonable to hold that these challenges by Kass and others have been met satisfactorily, it is possible to put forward additional considerations against their objections based on lack of uniqueness. Specifically, it can be pointed out that in the future it may be possible to combine cloning with genetic modification so that the child would have a unique set of nuclear genes. Scientific advances may enable us to add and delete genes in an individual human cell. Let us again assume, for the sake of argument, that such modifications could be carried out safely. Cloning could be performed using a cell nucleus from one member of an infertile couple. This could be followed by gene replacements in the pre-embryo, giving the child characteristics different from the parent whose nucleus was used. Alternatively, gene replacements could be carried out on the cell nucleus prior to cloning. Examples of modifications could include changes in hair colour, eye colour, or skin complexion. Health related changes could also be made, such as replacing genes that cause infertility or susceptibilities to disease. The modifications need not involve attempts at non-disease genetic 
enhancement, such as improved intelligence or increased height, but could have as their primary aim the creation of a genetically related child with a unique set of nuclear genes. In this type of scenario, the objection based on lack of uniqueness would no longer be applicable. Not only would there be phenotypic uniqueness, which presumably would be present even if there were identical nuclear DNA, but there would also be nuclear DNA uniqueness. The child would not be a clone, but the techniques used would include the cloning of cells, presumably by somatic cell nuclear transfer. In this article, I consider the ethical permissibility of using cloning combined with genetic modification to create genetically related children when this frequent objection to cloning is taken out of the picture.

Another possible feature of the envisioned scenario is that the genetic modification could aim to give the child a nuclear DNA relationship to both members of an infertile couple. The member of the couple whose cell nucleus is used for cloning would contribute most of the genes that the child would have. The genetic modifications that would accompany the cloning could aim to duplicate certain selected genetic characteristics of the other member of the couple, such as hair or eye colour. The child would possess nuclear genetic characteristics of both parents. The use of cloning combined with genetic modification could therefore be attractive to some infertile couples because it would enable both members to have a nuclear DNA relationship to the child.

Given the assumption that genetic modification is possible, it could be asked whether the future infertility cases we are considering could be cured by gene therapy. If so, there would be no need for cloning as a method for helping infertile couples to have genetically related children. In reply, if gene therapy for infertility were possible, some couples would probably prefer that approach. However, not all causes of infertility will be remediable by adding or deleting genes. Some couples are infertile because the woman's ovaries have been surgically removed; for others, advancing age diminishes the capacity of ova to become fertilised. Nongenetic factors such as environmental toxins, radiation, or testicular trauma are believed to be responsible for some cases of infertility. ${ }^{17-19}$ Other cases could be multifactorial, with both genetic and environmental causes. Moreover, there may be a period in the future when gene insertion and deletion is possible, but not all of the genetic causes of infertility are known. Putting aside infertility cases, there would still be an issue concerning the use of cloning and genetic modification to allow lesbian and gay couples to have genetically related children.

Whether cloning combined with genetic modification in the scenarios being considered is ethically justifiable involves the following question: which has greater weight, the procreative freedom of couples in these scenarios, or the arguments against cloning combined with genetic modification? First I shall address this question in the context of infertile couples, and then consider the issue as it relates to lesbian and gay couples.

\section{INFERTILE COUPLES}

Why should the freedom of infertile couples to use cloning and genetic modification be valued? Given that the main reason under consideration for using such technology is to have genetically related children, we need to ask what reasons can be given to value the having of genetically related children. A strategy for exploring this question is to consider reasons that can be given for valuing genetically related children in the ordinary scenario in which couples beget by sexual intercourse and raise the children who are born. There is widespread agreement that procreative freedom in this ordinary scenario deserves respect and protection. If reasons for valuing freedom to procreate in the ordinary scenario are also applicable to the freedom to have genetically related children by cloning combined with genetic modification, that would constitute an important reason to respect freedom in the latter scenario.

Elsewhere I identified a number of reasons worthy of consideration that help to explain why persons find it meaningful to have genetically related children in the ordinary scenario. ${ }^{20}$ Because I have discussed these reasons in detail, including the application of several of them to cloning without genetic modification, ${ }^{1}$ I shall not repeat these here. Rather, I shall comment briefly on the applicability of these reasons to cloning combined with genetic modification. It will suffice to focus on two of the reasons. First, having a genetic child in the ordinary scenario may be valued by some, in part, because it involves participation in the creation of a child. Similarly, in the case of cloning and genetic modification, one can envision several ways in which both members of an infertile couple could participate in the creation of a child. The member who provides a cell nucleus for cloning would participate by contributing most of the genes for the child. This would involve a physical transfer in which chromosomes from that person's body would be in the initial pre-embryonic cell of the offspring. Moreover, the genetic modifications could aim to duplicate some of the nuclear genes of the other member of the couple, thereby allowing that member to participate genetically in the creation of the child. Although this may not involve the physical transfer of this member's genes, there would still be a genetic connection in the sense that certain chosen genes would be duplicated. Those genes would be identified, perhaps sequenced, and this information would be used in carrying out the genetic modification. In addition, regardless of whose cell nucleus is used for nuclear transfer, if the woman is capable of producing ova, she could have a genetic connection by providing mitochondrial DNA to the child. Moreover, if she is capable of gestating, she could participate by gestating and giving birth to the child.

Secondly, having genetic children in the ordinary scenario could be meaningful to a couple in part because they regard it as an affirmation of mutual love and acceptance. It can be a deep expression of acceptance to say to another, in effect: "I want your genes to contribute to the genetic makeup of my child." In such a context, there may be an anticipation that the bond between the couple will grow stronger because of children in common to whom each has a genetic relationship. A similar affirmation of mutual love is possible when combining cloning and genetic modification. The couple create a child who has genetic characteristics of both members. Although infertility denies them the ability to contribute equally to the genetic makeup of the child, at least they have a method by which each can make a genetic contribution. In addition, when the man's cell nucleus is used and the woman gestates, the child comes forth from their two bodies.

In discussing these reasons, I do not mean to imply that one ought to desire genetic offspring, or that one ought to desire cloning combined with genetic modification as a way to have genetically related children. Rather, the point is that the desire for genetic children-and hence the desire for cloning combined with genetic alteration in the scenarios being considered-could be supported by reasons that deserve consideration. Although not everyone in the infertile couple's situation would want to pursue these methods, some might. These reasons help to explain why the freedom to use cloning combined with genetic modification to create a child with a genetic relationship to both members should be valued. 


\section{OBJECTIONS TO CLONING COMBINED WITH GENETIC MODIFICATION}

In the type of scenario we are considering, the objection based on lack of genetic uniqueness does not apply. However, there are other objections that could be raised against cloning combined with genetic modification.

\section{High genetic similarity to one parent}

An objection could focus on the fact that the child would be very similar genetically to the parent whose cell nucleus is used. Because of this close genetic similarity, there could be a tendency for that parent's life to be regarded as a standard to be met or exceeded by the child. If the child feels pressured to accept that standard, this may be a significant impediment to freedom in directing his or her own life.

In reply, this objection is similar to that to cloning based on lack of uniqueness, in that it is based on the view that genes determine who we are. As I argued above, even if there is identical nuclear DNA, one would expect significant differences between the child and the progenitor because of environmental influences. Similarly, when there is less than full duplication of genes, one would expect important differences. Moreover, parents' lives are often held up as standards, even in the absence of cloning and genetic modification. This can be either bad or good for a child, depending on how it is handled. It has the potential to inhibit as well as to promote development of the child's talents, abilities, and autonomy. Similarly, giving a role model or standard to a child created through cloning combined with genetic modification is not necessarily bad. It depends on how the standard is regarded and used by the parents. If it is used in a loving and nurturing manner, it can help children to develop their autonomy, rather than inhibit it.

If there is a concern that some parents could have rigid expectations concerning what their child should accomplish, or might otherwise set inappropriate standards, this topic could be addressed in preconception counselling. Psychological counselling is already widely accepted in preparing infertile couples for various non-coital reproductive methods, such as surrogate motherhood and donor insemination. Couples planning to use cloning combined with genetic modification could be counselled about the psychological dimensions of this method of procreation, including a possible tendency to assume, erroneously, that a close genetic similarity will determine the life path that the child will follow.

\section{Objectification of children}

Another objection is that cloning combined with genetic modification would transform babymaking into a process similar to manufacturing. Children would become products made according to specification. This would objectify children and adversely affect parental attitudes toward children and other aspects of parent-child relationships. ${ }^{21}{ }^{22}$ This argument arises from reflection on what it would be like if there were a widespread practice of designing the genetic characteristics of our children. The designing envisioned includes enhancing offspring's non-disease characteristics, such as height, intelligence, and body build; it is especially these types of genetic manipulations that raise concerns about undesirable changes in the attitudes and expectations of parents toward their children.

However, a reply can be made. Although these are important concerns, their bearing on the cases being considered is at best indirect. These cases do not involve efforts to enhance non-disease characteristics. They do not aim to make the child smarter, taller, stronger, or faster. Rather they aim to create a child who is genetically related to both members of a couple and who has unique genes. Thus, the concerns expressed above that are specific to trying to improve the child's abilities do not directly apply. The claim that the genetic modification in question would objectify the child is also weakened by the fact that a purpose of the modification is to give the child his or her own unique set of nuclear genes.

It could be objected that permitting genetic modification to create a child who is genetically related and genetically unique would set a precedent for other types of genetic modifications, including enhancement of non-disease characteristics. If we permit the former, it could be argued, it becomes more difficult to prevent the latter. One can reply to this objection without taking a position on the desirability of permitting enhancement of non-disease characteristics. The reply need only point out that, as the objection assumes, we can distinguish between cases that involve enhancement of non-disease characteristics and those that do not. Given that we can make this distinction, we can adopt policies that deal with these various types of genetic modification in different ways, if we choose to do so. If there were a plausible concern that a widespread practice of genetic non-disease enhancement would be harmful, there would be a middle ground that could be taken. Cloning combined with genetic modification could be restricted to a relatively small number of cases, such as those in which these techniques are the only way to produce genetically related children. In addition, the modifications could be restricted, if it were reasonably considered important to do so, to those that aim to give the child unique nuclear DNA and a genetic relationship to both members of a couple.

\section{LESBIAN COUPLES}

It has been suggested that lesbian couples might want to use cloning to have children. ${ }^{2}$ Cloning could be attractive to some lesbian couples because it avoids third-party collaboration. Some might prefer to avoid the social complications that can arise when a semen donor who is known to them is involved; and some may prefer not to use anonymous semen donors because the child might later desire to meet the genetic father, a desire that could not be fulfilled. Taking it a step further, cloning combined with genetic modification could be requested by some lesbian couples because it not only avoids the use of sperm donors but permits them to have a child who has genetic characteristics of both of them and who has a unique set of nuclear genes.

Most of the reasons that make procreation meaningful to heterosexual couples in the ordinary scenario would be applicable to the use of cloning combined with genetic modification by lesbian couples. For example, this technique would permit the couple to participate more fully in the creation of a person. One member of the couple could provide the nuclear genes, and the other could provide the ovum with its associated mitochondrial genes. Genetic modification could duplicate selected genes of the member who does not provide the cell nucleus. Either member could participate by gestating and giving birth to the child. The fact that both members contribute genes to the child could also be meaningful to the couple as an affirmation of mutual love and acceptance.

The objections that have been raised against reproductive cloning combined with genetic modification, which were discussed above, could be raised in the context of such procreative methods being used by lesbian couples. However, the responses that were discussed above would again be applicable, and therefore the objections are also unsuccessful in this context.

Putting aside concerns about cloning, some have objected to any type of assisted reproduction for lesbian couples. One issue is that children raised in lesbian households will 
become homosexual themselves. Other versions of the objection claim that these children would be harmed by various factors associated with being raised by lesbians, including social stigma, the lack of a male role model, and the lower incomes of women compared with men. In reply, several points can be made. First, the objection makes the mistake of assuming that being homosexual is inherently harmful, as opposed to being a condition in which harms arise because of the prejudices of others. This assumption seems itself to reflect a prejudice against homosexuals. Secondly, the claim that the children produced would have an increased tendency to become homosexual is not confirmed by the evidence. A number of studies have supported the conclusion that there is no increased incidence of homosexuality in children raised by lesbians in comparison with children raised in heterosexual households. ${ }^{23}$ Thirdly, even if the various purported harms were to happen, it would be a mistake to think that their likely occurrence would make it unethical to create the child. The problem is that the objection focuses exclusively on harms to the child, without consideration of benefits to the child. It makes this mistake because it overlooks the fact that without the procreation in question the child would not exist. If one holds that lesbians bringing a child into existence can harm the child, then one must also hold that lesbians bringing a child into being can benefit the child. It would be arbitrary to make one claim but deny the other. In assessing this objection, we need to consider the benefits as well as the harms. There would be benefits; after all, the procreation would give the child a life. Life generally is a good thing. Presumably the child would have many good experiences associated with being alive, and it is reasonable to expect that the benefits are going to outweigh the harms - that the child would have a good life on balance. If the child benefits on balance, then no wrong is done in creating him or her, at least as far as harms and benefits are concerned.

Perhaps it will be objected that procreation by lesbians is wrong because some harms will occur to the child, although admittedly not a net harm. However, the assertion that it is wrong to create children who will experience harms, although not a net harm, leads to unacceptable conclusions. We would have to say, for example, that it is wrong for fertile minority couples who are subject to discrimination to have children because the children would suffer harms caused by discrimination. Surely, this would be an incorrect conclusion. The objection amounts to saying that it is wrong to reproduce when some ideal of freedom from harm cannot be satisfied. However, there is no obligation to have children only if their lives will be free from harm, as this counterexample illustrates.

\section{GAY COUPLES}

It has been pointed out that gay couples might wish to use cloning as a means of having children. ${ }^{2}$ However, the main arguments that have been put forward supporting the ethical permissibility of infertile couples and lesbian couples using cloning without genetic modification would not be applicable to gay couples. Those arguments rest on the fact that there are scenarios in which the aims of cloning by infertile and lesbian couples would be to have a child who is genetically related to one member of the couple and to avoid third-party collaborative reproduction. ${ }^{125}$ For gay couples, it would be possible to create a child genetically related to one member by means other than cloning, assuming individual fertility. For example, sperm from one of the men could be combined with a donor egg, and a resulting pre-embryo could be implanted in a woman willing to bear the child. The availability of this alternative raises the question of why a gay couple would want to use cloning. The reason could not be to avoid third-party collaborative reproduction because that is not possible; cloning a gay man would require an ovum donor and a surrogate mother. Therefore, the purpose of cloning without genetic modification, in the case of gay couples, would not be to have a child who is genetically related to one member of the couple while avoiding third-party collaborative reproduction.

When cloning is combined with genetic modification, however, a new rationale becomes available for gay couplesto have a child who shares genetic characteristics of both members of the couple. Several of the reasons that make procreation meaningful to heterosexual couples in the ordinary scenario would apply to the use of cloning combined with genetic modification by gay couples. It would enable both members to participate in the creation of a person. One member would provide nuclear genes and genetic modifications could duplicate selected genes of the other member. Creating a child with genetic similarities to both could also be meaningful to a couple as an expression of mutual love and acceptance. In addition, this would be a means towards the experiences of child rearing. These considerations suggest that the reproductive freedom of gay couples to use cloning combined with genetic modification deserves respect because it can be based on some of the same reasons that make reproductive freedom generally worth protecting. The objections to lesbian couples having children could also be raised against gay couples having children. However, those objections again fail, for the same reasons.

\section{CONCLUSION}

In conclusion, I have argued that cloning combined with certain types of genetic modifications can be ethically justifiable when carried out by infertile, lesbian, or gay couples as a means to have children with a genetic relationship to both members of the couple. My focus on these types of cases should not be taken to imply that there are no other types of scenario in which cloning combined with genetic modification would be ethically justifiable.

Competing interests: none declared

\section{REFERENCES}

1 Strong C. Cloning and infertility. Camb Q Healthc Ethics 1998;7:279-93.

2 Murphy T. Entitlement to cloning. Camb Q Healthc Ethics 1999;8:364-8.

3 National Academy of Sciences. Scientific and medical aspects of human reproductive cloning. Washington, DC: National Academy Press, 2002:1 1-12,39-42.

4 Holm S. A life in the shadow: one reason why we should not clone humans. Camb Q Healthc Ethics 1998;7:160-2.

5 President's Council on Bioethics. Human cloning and human dignity: an ethical inquiry. Washington, DC, 2002:102-4,110-11, http:// www. bioethics.gov (accessed 30 Mar 2005)

6 National Bioethics Advisory Commission. Cloning human beings. Rockville, MD, 1997:66-72. http://www.georgetown.edu/research/nrcbl/nbac/ pubs.html (accessed 30 Mar 2005).

7 Williamson R. Human reproductive cloning is unethical because it undermines autonomy: commentary on Savulescu. J Med Ethics 1999;25:96-7.

8 Shuster E. Human cloning: category, dignity, and the role of bioethics. Bioethics 2003;17:517-25.

9 Massey JB, Slayden S, Shapiro DM, et al. Unnatural deeds do breed unnatural troubles (Macbeth: Act v, Scene 1) [letter]. Fertil Steril $2001 ; 76: 1083-4$

10 Häyry M. Philosophical arguments for and against human reproductive cloning. Bioethics 2003;17:447-59.

11 Lewontin R. The confusion over cloning. In: McGee G, ed. The human cloning debate. Berkeley, CA: Berkeley Hills Books, 2000:154-69.

12 Simpson JL. Toward scientific discussion of human reproductive cloning. Reprod Biomed Online 2003;7:10-11.

13 Gould SJ. Dolly's fashion and Louis's passion. In: Pence GE, ed. Flesh of my flesh: the ethics of cloning humans. Lanham, MD: Rowman and Littlefield, 1998:101-10.

14 Harris J. Clones, genes, and immortality. Oxford: Oxford University Press, 1998:27-8

15 Eisenberg L. Would cloned humans really be like sheep? N Engl J Med 1999;340:471-5.

16 Johnson G. Soul searching. In: Nussbaum MC, Sunstein CR, eds. Clones and clones: facts and fantasies about human cloning. New York, NY: Norton, 1998:67-70 
17 Kenkel S, Rolf C, Nieschlag E. Occupational risks for male fertility: an analysis of patients attending a tertiary referral centre. Int $J$ Androl $2001 ; 24: 318-26$

18 Howell S, Shalet $\mathrm{S}$. Fertility preservation and management of gonadal failure associated with lymphoma therapy. Curr Oncol Rep 2002:4:443-52.

19 Nolten WE, Vioska SP, Korenman SG, et al. Association of elevated estradiol with remote testicular trauma in young infertile men. Fertil Steril 1994;62:143-9.

20 Strong C. Ethics in reproductive and perinatal medicine: a new framework. New Haven, CT: Yale University Press, 1997:18-22.
21 Botkin JR Prenatal screening professional standards and the limits of parental choice. Obstet Gynecol 1990;75:875-80.

22 Strong C. Tomorrow's prenatal genetic testing: should we test for "minor" diseases? Arch Fam Med 1993;2:1187-93.

23 Tasker F, Golombok S. Adults raised as children in lesbian families. Am J Orthopsychiatry 1995;65:203-15

24 Golombok S, Spencer A, Rutter M. Children in lesbian and single-parent households: psychosexual and psychiatric appraisal. J Child Psychol Psychiatry 1983;24:551-72.

25 Strong C. Clone alone. Camb Q Healthc Ethics 2002;11:76-82.

\section{Clinical Evidence-Call for contributors}

Clinical Evidence is a regularly updated evidence-based journal available worldwide both as a paper version and on the internet. Clinical Evidence needs to recruit a number of new contributors. Contributors are healthcare professionals or epidemiologists with experience in evidence-based medicine and the ability to write in a concise and structured way.

Areas for which we are currently seeking contributors:

- Pregnancy and childbirth

- Endocrine disorders

- Palliative care

- Tropical diseases

We are also looking for contributors for existing topics. For full details on what these topics are please visit www.clinicalevidence.com/ceweb/contribute/index.jsp

However, we are always looking for others, so do not let this list discourage you.

Being a contributor involves:

- Selecting from a validated, screened search (performed by in-house Information Specialists) epidemiologically sound studies for inclusion.

- Documenting your decisions about which studies to include on an inclusion and exclusion form, which we keep on file.

- Writing the text to a highly structured template (about 1500-3000 words), using evidence from the final studies chosen, within 8-10 weeks of receiving the literature search.

- Working with Clinical Evidence editors to ensure that the final text meets epidemiological and style standards.

- Updating the text every 12 months using any new, sound evidence that becomes available. The Clinical Evidence in-house team will conduct the searches for contributors; your task is simply to filter out high quality studies and incorporate them in the existing text.

If you would like to become a contributor for Clinical Evidence or require more information about what this involves please send your contact details and a copy of your CV, clearly stating the clinical area you are interested in, to CECommissioning@bmigroup.com.

\section{Call for peer reviewers}

Clinical Evidence also needs to recruit a number of new peer reviewers specifically with an interest in the clinical areas stated above, and also others related to general practice. Peer reviewers are healthcare professionals or epidemiologists with experience in evidence-based medicine. As a peer reviewer you would be asked for your views on the clinical relevance, validity, and accessibility of specific topics within the journal, and their usefulness to the intended audience (international generalists and healthcare professionals, possibly with limited statistical knowledge). Topics are usually 1500-3000 words in length and we would ask you to review between 2-5 topics per year. The peer review process takes place throughout the year, and out turnaround time for each review is ideally 10-14 days.

If you are interested in becoming a peer reviewer for Clinical Evidence, please complete the peer review questionnaire at www. clinicalevidence.com/ceweb/contribute/peerreviewer.jsp 